\title{
FUZZY INVENTORY MODEL FOR DETERIORATING ITEMS IN A SUPPLY CHAIN SYSTEM WITH TIME DEPENDENT DEMAND RATE
}

\author{
Srabani Shee \\ Department of Applied Mathematics, \\ University of Calcutta, \\ 92 A.P.C. Road, Kolkata-700009, India
}

\begin{abstract}
An inventory model for a single deteriorating item under fuzzy environment has been presented in this paper. Here demand rate is considered to be constant for some time period, post which the same is a linear function of time. This situation is common during the time of a new product launch in the market. As the product becomes popular, its demand increases with time although it remains constant during the initial days. Cycle time is considered to be constant in most of the models. However, practically it has been observed that it is difficult to pro-actively predict the cycle time. Because of this problem, cycle time has been considered as uncertain and has been further described as Symmetric Triangular Fuzzy number. The Signed Distance method has been used for defuzzification of the total cost function. For illustration of the process for finding the total optimal cost and the cycle time, numerical examples have been considered. The effects of changing parameter values on the optimal solution of the system have been demonstrated through Sensitivity Analysis.
\end{abstract}

Keywords - Supply Chain Management, Constant and Time Dependent Demand rate, Deterioration, Symmetric Triangular Fuzzy number, Signed Distance Method

\section{INTRODUCTION}

The most important and difficult role that inventory plays in Supply chain is that of facilitating the balancing of demand and supply. To effectively manage the forward and reverse flows in the supply chain, firms have to deal with upstream supplier exchanges and downstream customer demands. Uncertainty is another key issue to deal with in order to define effective Supply Chain inventory policies. Demand, Supply (e.g. lead time), various relevant cost, backorder
Tripti Chakrabarti

Dean of Basic Science, Techno India

University, Kolkata, India

(Formerly Professor of Applied Mathematics, University of Calcutta, Kolkata, India)

costs, deterioration rate etc. are usually uncertain. To solve these types of practical problems we use the Fuzzy Set Theory. Bellman and Zadeh (1970) (1) first studied fuzzy set theory to solve decision making problem. Then, Dubois and Prade (1978) (2) introduced some operations on fuzzy number. Thereafter, Park (1987) (3) developed fuzzy set theoretical interpretation of EOQ. Several researchers like K. Wu and J. S. Yao (2003) (4), X. Wang and R. Zhao (2007) (5), Hu Jinsong et al. (2010) (6), K. Jaggi et al. (2013) (16), J. S. Yao and J. Chiang (2003) (17), X. Wang et al. (2007) (18), C. Kao and W. K. Hsu (2002) (19), P. Dutta et al. (2005) (20), A. Roy and G. P. Samanta (2009) (15) have developed different types of inventory model under Fuzzy environment. In this area, a lot of research papers have been published by several researchers viz., Bera, Bhunia, and Maiti (2013) (21), He, Wei, and Fuyuan (2013) (22), Dutta and Kumar (2015) (23), Mishra et al. (2015) (24) etc. S. Priyan, P. Manivannan (2017) (25) developed an optimal inventory modelling of supply chain system involving quality inspection errors in Fuzzy situation.

C. Lin, B. Tan, and W. C. Lee et al. (2000) (7) and Mishra et al. (2015) (9) developed an economic order quantity model that focused on time varying demand and deteriorating items. After that, S. K. Ghosh and K. S. Chaudhuri (2004) (8) proposed an inventory model with Weibull distribution rate of deterioration, time quadratic demand and shortages. A lot of research papers have been published by several researchers viz., $\mathrm{T}$. Y. Wang and L. H. Chen (2001) (10), A. K. Pal, A. K. Bhunia and R. N. Mukherjee (2006) (11), U. K. Bera, A. K. Bhunia and M. Maiti (2013) (12), W. He, H. E. Wei and X. U. Fuyuan (2013) (13), D. Dutta and P. Kumar (2015) (14) etc.. 
This paper has presented a Fuzzy supply chain inventory model in which the demand rate is constant for some time and then it increases or decreases according to the popularity of the product. This type of situation occurs when a new product is launched in the market. When the product becomes popular the demand of the product increases with time. It is also assumed that the cycle time is taken as Symmetric Triangular Fuzzy number. In addition, expressions for order quantity, cycle time and the total average cost (for both the models) are obtained. The convexity of the total cost function is established to ensure the existence of a unique optimal solution. The problem is solved by using LINGO 17.0 software.

\section{ASSUMPTIONS AND NOTATIONS}

The proposed model is developed under the following notations and assumptions:

\section{Notations:}

1. $I(t)$ is the inventory level at time $t(\geq 0)$.

2. Demand $R(t)=$ $\left\{\begin{array}{l}a \quad, \text { for } 0 \leq t \leq \mu \\ a+b(t-\mu), \text { for } \mu \leq t \leq T\end{array}\right.$.

3. $\theta$ is the rate of deterioration.

4. $\quad q$ is the number of items received at the beginning of the period.

5. $C$ is the deterioration cost per unit.

6. $C_{1}$ is the inventory holding cost per unit per unit time.

7. $C_{2}$ is the Set-up cost per cycle.

8. $\mu$ is the time point at which deterioration starts and also demand increases with time.

9. $T$ is the cycle length.
10. $\tilde{T}$ is the fuzzy cycle length.

11. $K(t)$ is the total inventory cost of the system per unit time.

12. $\widehat{K(t)}$ is the fuzzy total inventory cost of the system.

\section{Assumptions:}

1. The deterioration cost, holding cost and ordering cost remain constant over time.

2. There is no deterioration for the period $[0, \mu]$. The deterioration rate is constant, say $\theta$, for the period $[\mu, T]$, which is practically very small.

3. A single item is considered over a prescribed period of $\mathrm{T}$ units of time.

4. The cycle time is uncertain and we assume it as symmetric triangular fuzzy number.

5. The replenishment is instantaneous.

6. Lead time is zero.

7. There is no replacement or repair of deteriorated items.

8. Shortage is not allowed.

\section{MATHEMATICAL MODEL}

The inventory cycle starts at time $t=0$ with the inventory level $q$. During the time interval $[0, \mu]$, the inventory level decreases due to the constant demand $a$ units per unit time. After time $t=\mu$, the inventory level gradually decreases mainly to meet demands and partly for deterioration and falls to zero at time $t=T$. The cycle then repeats itself after time $T$.

This model is represented by the following diagram:

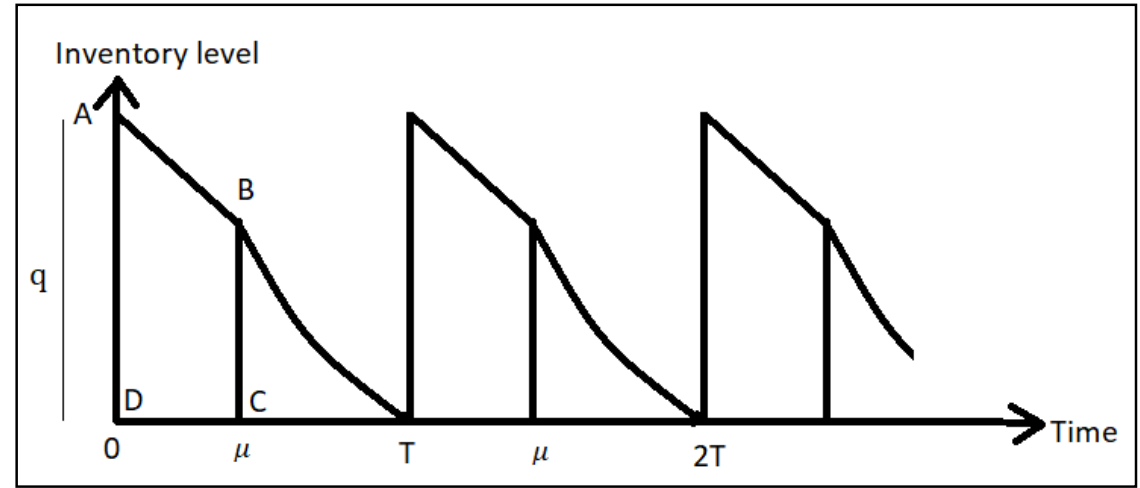

Now, the total demand for the time period $[0, \mu]$, is $=a \mu$.

Therefore, the inventory level is decreased by the factor $a \mu$ and $(q-a \mu)$ inventory is left for the time period $[\mu, T]$.
The holding cost for the period $[0, \mu]$ is

$$
\begin{aligned}
& =C_{1}(\text { Area of trapezium } A B C D) \\
& =C_{1} \cdot \frac{1}{2}[q+(q-a \mu)] \mu
\end{aligned}
$$




$$
=C_{1} \mu\left[(q-a \mu)+\frac{a \mu}{2}\right]
$$

Then, the differential equation governing the instantaneous state of $I(t)$ during the time interval $\mu \leq t \leq t_{1}$ is,

$$
\frac{d I(t)}{d t}=-\theta I(t)-[a+b(t-\mu)], \quad 0 \leq t \leq t_{1}
$$

[Where $t_{1}=(T-\mu)$, the origin has been shifted just for the sake of mathematical simplicity.]

With the boundary conditions, $t=0, I(t)=(q-a \mu)$ and $t=t_{1}, I(t)=0$

Solving the differential equation we get,

$e^{\theta t} I(t)-(q-a \mu)=-\int_{0}^{t}[a+b(t-\mu)] e^{\theta t} d t$

At $t=t_{1}, I(t)=0$

$\therefore(q-a \mu)=\int_{0}^{t_{1}}[a+b(t-\mu)] e^{\theta t} d t$

We know that $e^{\theta t}=\sum_{n=0}^{\infty} \frac{(\theta t)^{n}}{n !}$. Using this exponential expansion in the equation (2) and then integrating term bay term we have,

$(q-a \mu)=(a-b \mu) \sum_{n=0}^{\infty} \frac{\theta^{n}}{n !} \frac{t_{1}{ }^{n+1}}{n+1}+b \sum_{n=0}^{\infty} \frac{\theta^{n}}{n !} \frac{t_{1}{ }^{n+2}}{n+2}$

Now, the holding cost for the time period $\left(0, t_{1}\right)$ is

$$
=C_{1} \frac{1}{2}(q-a \mu) t_{1}
$$

Total amount of inventory that has deteriorated during this cycle is

$$
\begin{aligned}
& =(q-a \mu)-\int_{0}^{t_{1}}[a+b(t-\mu)] e^{\theta t} d t \\
& =(q-a \mu)-(a-b \mu) t_{1}-\frac{1}{2} b t_{1}{ }^{2}
\end{aligned}
$$

Therefore, the total inventory cost per unit time is,

$K(T)=$ inentory carrying cost + deterioration cost + set up cost

$$
\begin{aligned}
&=\frac{1}{T}\left[C_{1} \mu(q-a \mu)+C_{1} \frac{a \mu^{2}}{2}+\frac{1}{2} C_{1}(q-a \mu) t_{1}+C\left\{(q-a \mu)-(a-b \mu) t_{1}-\frac{1}{2} b t_{1}{ }^{2}\right\}+C_{2}\right] \\
&=\frac{1}{T}\left[(q-a \mu)\left\{C_{1} \mu+\frac{1}{2} C_{1} t_{1}+C\right\}+C_{1} \frac{a \mu^{2}}{2}-C(a-b \mu) t_{1}-\frac{C}{2} b t_{1}{ }^{2}+C_{2}\right] \\
&=\frac{1}{T}\left[\left(C_{1} \mu+C\right)\left\{(a-b \mu) \sum_{n=0}^{\infty} \frac{\theta^{n}}{n !} \frac{(T-\mu)^{n+1}}{n+1}+b \sum_{n=0}^{\infty} \frac{\theta^{n}}{n !} \frac{(T-\mu)^{n+2}}{n+2}\right\}+\frac{C_{1}}{2}\left\{(a-b \mu) \sum_{n=0}^{\infty} \frac{\theta^{n}}{n !} \frac{(T-\mu)^{n+2}}{n+1}+\right.\right. \\
&\left.\left.b \sum_{n=0}^{\infty} \frac{\theta^{n}}{n !} \frac{(T-\mu)^{n+3}}{n+2}\right\}+C_{1} \frac{a \mu^{2}}{2}-C(a-b \mu)(T-\mu)-\frac{C}{2} b(T-\mu)^{2}+C_{2}\right]
\end{aligned}
$$

Since $\theta$ is very small, the terms involving $\theta^{n}$ with $n(>1)$ can be neglected. Hence, retaining the terms in the summation for $n=0$ and $n=1$ only, we have,

$$
\begin{aligned}
& K(T)=\frac{1}{T}\left[P\left\{A(T-\mu)+\frac{A \theta}{2}(T-\mu)^{2}+\frac{b}{2}(T-\mu)^{2}+\frac{b \theta}{3}(T-\mu)^{3}\right\}\right. \\
&+\left.\frac{C_{1}}{2}\left\{A(T-\mu)^{2}+\frac{A \theta}{2}(T-\mu)^{3}+\frac{b}{2}(T-\mu)^{3}+\frac{b \theta}{3}(T-\mu)^{4}\right\}+C_{1} \frac{a \mu^{2}}{2}-C A T+C A \mu\right) \\
&\left.-\frac{C}{2} b(T-\mu)^{2}+C_{2}\right]
\end{aligned}
$$




$$
\begin{array}{r}
\quad=\frac{C_{1} b \theta}{6} T^{3}+\left(-\frac{2}{3} \mu C_{1} b \theta+\frac{P b \theta}{3}+\frac{C_{1} A \theta}{4}+\frac{C_{1} b}{4}\right) T^{2}+\left(C_{1} b \theta \mu^{2}-P b \theta \mu-\frac{3 C_{1} A \theta \mu}{4}-\frac{3 C_{1} b \mu}{4}+\frac{P A \theta}{2}+\frac{P b}{2}+\right. \\
\left.\frac{C_{1} A}{2}-\frac{C b}{2}\right) T+\left(-\frac{2}{3} C_{1} b \theta \mu^{3}+P b \theta \mu^{2}+\frac{3}{4} C_{1} A \theta \mu^{2}+\frac{3}{4} C_{1} b \mu^{2}-P A \theta \mu-P b \mu-C_{1} A \mu+C b \mu+P A-C A\right)+ \\
\left(\frac{C_{1} b \theta \mu^{4}}{6}-\frac{P b \theta \mu^{3}}{3}-\frac{C_{1} A \theta \mu^{3}}{4}-\frac{C_{1} b \mu^{3}}{4}+\frac{P A \theta \mu^{2}}{2}+\frac{P b \mu^{2}}{2}+\frac{C_{1} A \mu^{2}}{2}-\frac{C b \mu^{2}}{2}-P A \mu+C A \mu+C_{1} \frac{a \mu^{2}}{2}+C_{2}\right) \frac{1}{T} \\
=U_{1} T^{3}+V_{1} T^{2}+W_{1} T+X_{1}+Y_{1} \frac{1}{T}
\end{array}
$$

Where, $P=\left(C_{1} \mu+C\right)$ and $A=(a-b \mu)$

$$
\begin{aligned}
& U_{1}=\frac{C_{1} b \theta}{6} \\
& V_{1}=\left(-\frac{2}{3} \mu C_{1} b \theta+\frac{P b \theta}{3}+\frac{C_{1} A \theta}{4}+\frac{C_{1} b}{4}\right) \\
& W_{1}=\left(C_{1} b \theta \mu^{2}-P b \theta \mu-\frac{3 C_{1} A \theta \mu}{4}-\frac{3 C_{1} b \mu}{4}+\frac{P A \theta}{2}+\frac{P b}{2}+\frac{C_{1} A}{2}-\frac{C b}{2}\right) \\
& X_{1}=\left(-\frac{2}{3} C_{1} b \theta \mu^{3}+P b \theta \mu^{2}+\frac{3}{4} C_{1} A \theta \mu^{2}+\frac{3}{4} C_{1} b \mu^{2}-P A \theta \mu-P b \mu-C_{1} A \mu+C b \mu+P A-C A\right) \\
& Y_{1}=\left(\frac{C_{1} b \theta \mu^{4}}{6}-\frac{P b \theta \mu^{3}}{3}-\frac{C_{1} A \theta \mu^{3}}{4}-\frac{C_{1} b \mu^{3}}{4}+\frac{P A \theta \mu^{2}}{2}+\frac{P b \mu^{2}}{2}+\frac{C_{1} A \mu^{2}}{2}-\frac{C b \mu^{2}}{2}-P A \mu+C A \mu+C_{1} \frac{a \mu^{2}}{2}+C_{2}\right)
\end{aligned}
$$

Now, let us describe the cycle time $T$ as triangular fuzzy number $\widetilde{T}=(T-\Delta, T, T+\Delta)$.

So, from the equation (5) the total Fuzzy cost function is-

$$
\widetilde{K(T)}=U_{1} \tilde{T}^{3}+V_{1} \tilde{T}^{2}+W_{1} \tilde{T}+X_{1}+Y_{1} \frac{1}{\tilde{T}}
$$

From the definition of the Signed distance method we have,

$$
d(\tilde{A}, 0)=\frac{1}{2} \int_{0}^{1}\left[A_{L}(\alpha)+A_{U}(\alpha)\right] d \alpha
$$

Where, $\tilde{A}=(a, b, c), A_{L}(\alpha)=a+(b-a) \alpha, A_{U}(\alpha)=c-(c-b) \alpha$

Now, $T_{L}(\alpha)=(T-\Delta)+\Delta \alpha, T_{U}(\alpha)=(T+\Delta)-\Delta \alpha$

Therefore, $d(\tilde{T}, 0)=\frac{1}{2} \int_{0}^{1}\left[T_{L}(\alpha)+T_{U}(\alpha)\right] d \alpha$

$$
\begin{aligned}
& =\frac{1}{2} \int_{0}^{1}[(T-\Delta)+\Delta \alpha+(T+\Delta)-\Delta \alpha] d \alpha \\
& =\frac{1}{2} \int_{0}^{1} 2 T d \alpha=T
\end{aligned}
$$

And $d\left(\frac{1}{\tilde{T}}, 0\right)=\frac{1}{2} \int_{0}^{1}\left[\left(\frac{1}{\tilde{T}}\right)_{L}(\alpha)+\left(\frac{1}{\tilde{T}}\right)_{U}(\alpha)\right] d \alpha$

$$
\begin{aligned}
& =\frac{1}{2} \int_{0}^{1}\left[\frac{1}{T+\Delta-\Delta \alpha}+\frac{1}{T-\Delta+\Delta \alpha}\right] d \alpha \\
& =\frac{1}{2 \Delta} \ln \left(\frac{T+\Delta}{T-\Delta}\right)
\end{aligned}
$$

From (6), (7) and (8) we have-

$$
\widetilde{K(T)}=U_{1} T^{3}+V_{1} T^{2}+W_{1} T+X_{1}+\frac{1}{2 \Delta} Y_{1} \ln \left(\frac{T+\Delta}{T-\Delta}\right)
$$

To minimize $K(T)$ the necessary condition is

$\frac{d K(T)}{d T}=0$ 
By simplifying $\frac{d K(T)}{d T}=0$ we get a bi-quadratic equation in $T$, which is,

$3 U_{1} T^{4}+2 V_{1} T^{3}+W_{1} T^{2}-Y_{1}=0$

We can solve equation (5) by Newton-Raphson's method for a positive $T$ ( $T^{*}$ say)

If $\frac{d^{2} K(T)}{d T^{2}}>0$ for $T=T^{*}$, then $T^{*}$ will be an optimal solution.

Hence, $K(T)$ is strictly convex.

Substituting the value of $T=T^{*}$ in (5), the optimum average cost $K\left(T^{*}\right)$ can also be determined.

\section{NUMERICAL EXAMPLE}

To illustrate the results obtained for the suggested model, a numerical example with the following parameter values is considered.

$a=20$ units, $b=0.2, \mu=0.4$ days, $\theta=0.02$,

$C=R s .18$ per unit,
$C_{1}=$ Rs. 0.50per unit per day, $C_{2}=$ Rs. 80

We obtain for crisp model optimum total cost is $K\left(T^{*}\right)=50.4065$ per day.

and cycle time is $T^{*}=2.975$ days .

For fuzzy model total cost $\widetilde{K\left(T^{*}\right)}=53.5294$ and cycle time $\widetilde{T^{*}}=3.016$

The convexity of the total cost function is shown in Fig.1.

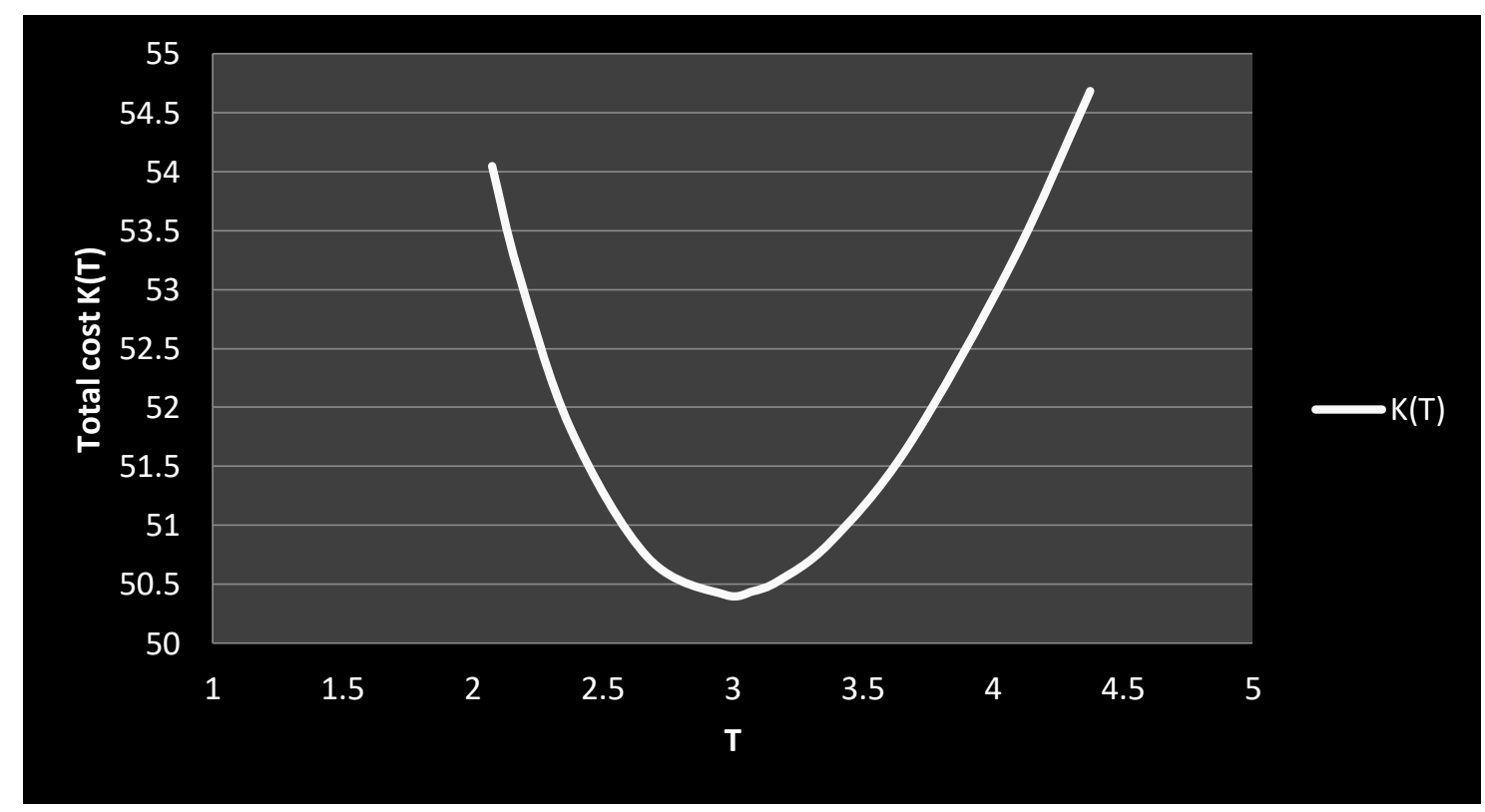

Fig.1 Convexity of cost function w. r. $t$ T

V. SENSITIVITY ANALYSIS

Table 1: Sensitivity on $\mu$ :

\begin{tabular}{|c|c|c|c|c|c|}
\hline \multicolumn{2}{|c|}{ Change Value } & \multicolumn{2}{|c|}{ Crisp model } & \multicolumn{2}{|c|}{ Fuzzy model } \\
\hline & & $K\left(T^{*}\right)$ & $T^{*}$ & $\widetilde{K\left(T^{*}\right)}$ & $\widetilde{T^{*}}$ \\
\hline \multirow[t]{6}{*}{$\mu$} & 0.1 & 52.5818 & 2.954 & 53.5589 & 2.995 \\
\hline & 0.2 & 51.8308 & 2.960 & 53.5247 & 3.001 \\
\hline & 0.3 & 51.1057 & 2.967 & 53.5148 & 3.008 \\
\hline & 0.4 & 50.4065 & 2.975 & 53.5294 & 3.016 \\
\hline & 0.5 & 49.7332 & 2.985 & 53.5684 & 3.025 \\
\hline & 0.6 & 49.0858 & 2.996 & 53.6318 & 3.036 \\
\hline
\end{tabular}


International Journal of Engineering Applied Sciences and Technology, 2020 Vol. 5, Issue 1, ISSN No. 2455-2143, Pages 558-569

Published Online May 2020 in IJEAST (http://www.ijeast.com)

\begin{tabular}{|l|l|l|l|l|l|}
\hline & 0.7 & 48.4643 & 3.009 & 53.7195 & 3.049 \\
\hline
\end{tabular}

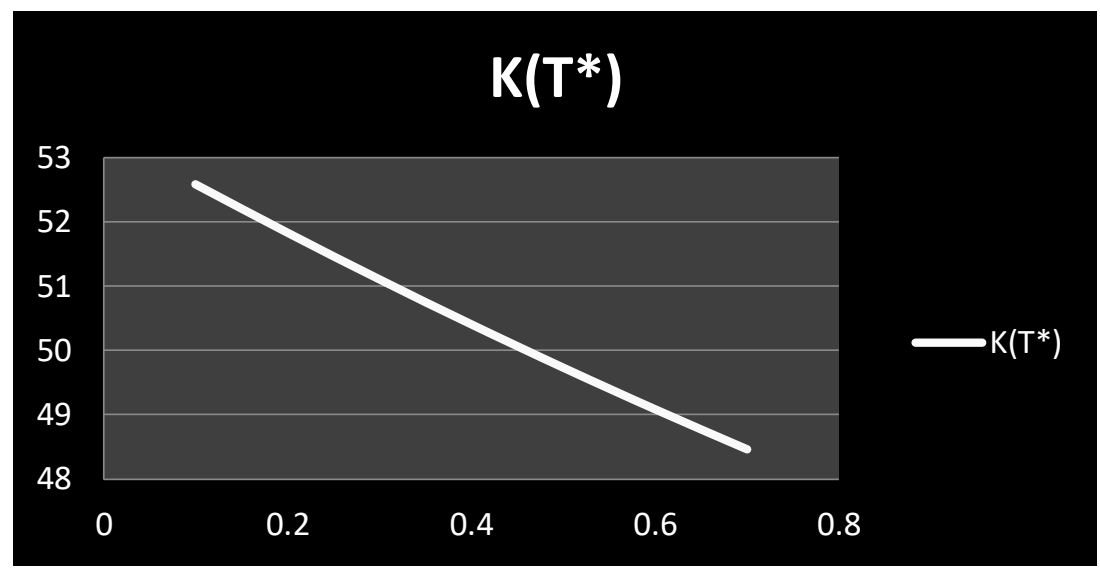

Fig. 2: Impact of $\mu$ on $K\left(T^{*}\right)$ : Crisp model

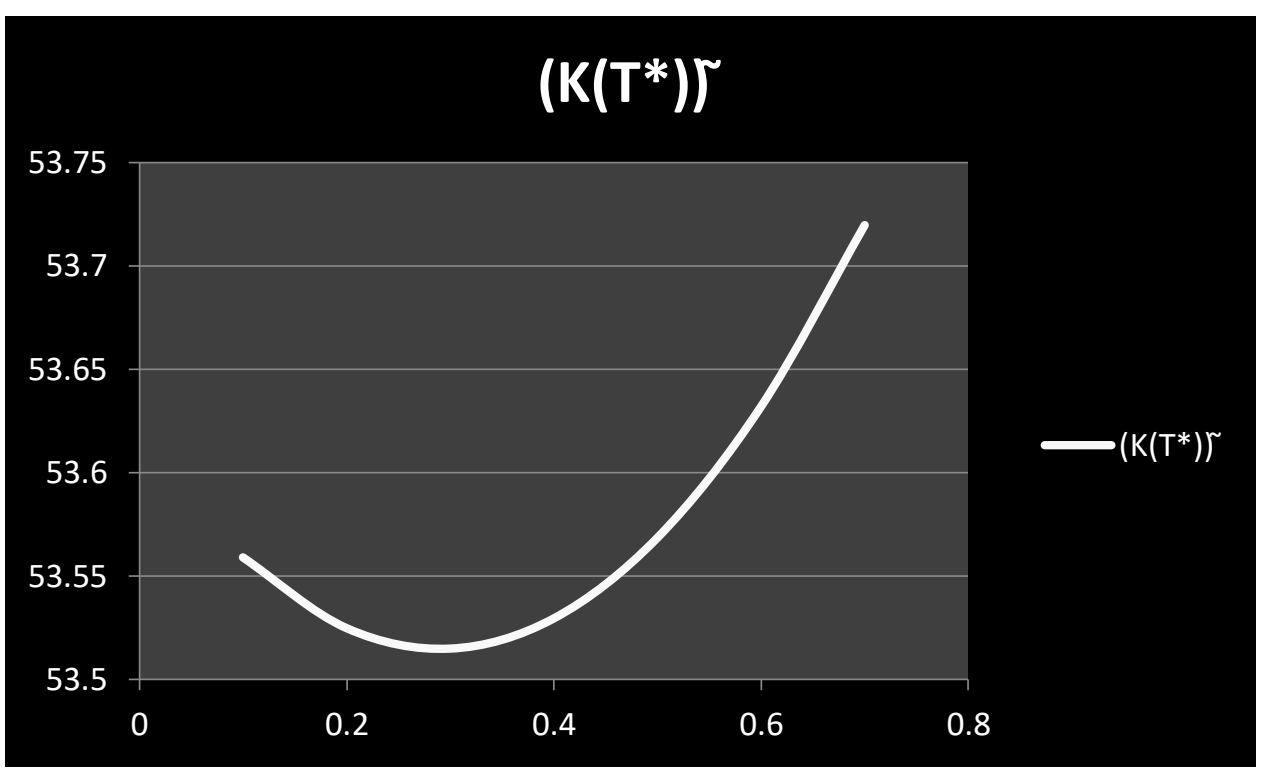

Fig. 3: Impact of $\mu$ on $\widetilde{K\left(T^{*}\right)}$ : Fuzzy model

Table 2: Sensitivity on $C_{2}$ :

\begin{tabular}{|c|c|c|c|c|c|}
\hline \multicolumn{2}{|c|}{ Change Value } & \multicolumn{2}{c|}{ Crisp model } & \multicolumn{2}{c|}{ Fuzzy model } \\
\cline { 3 - 6 } \multicolumn{2}{|c|}{} & $K\left(T^{*}\right)$ & $T^{*}$ & $\widetilde{K\left(T^{*}\right)}$ & $\widetilde{T}^{*}$ \\
\hline \multirow{3}{*}{$C_{2}$} & 60 & 43.2216 & 2.591 & 46.3794 & 2.637 \\
\cline { 2 - 6 } & 70 & 46.9379 & 2.790 & 50.0764 & 2.834 \\
\cline { 2 - 6 } & 80 & 50.4065 & 2.975 & 53.5294 & 3.016 \\
\cline { 2 - 6 } & 90 & 53.6722 & 3.148 & 56.7822 & 3.187 \\
\cline { 2 - 6 } & 100 & 56.7680 & 3.312 & 59.8670 & 3.348 \\
\hline
\end{tabular}


International Journal of Engineering Applied Sciences and Technology, 2020 Vol. 5, Issue 1, ISSN No. 2455-2143, Pages 558-569

Published Online May 2020 in IJEAST (http://www.ijeast.com)

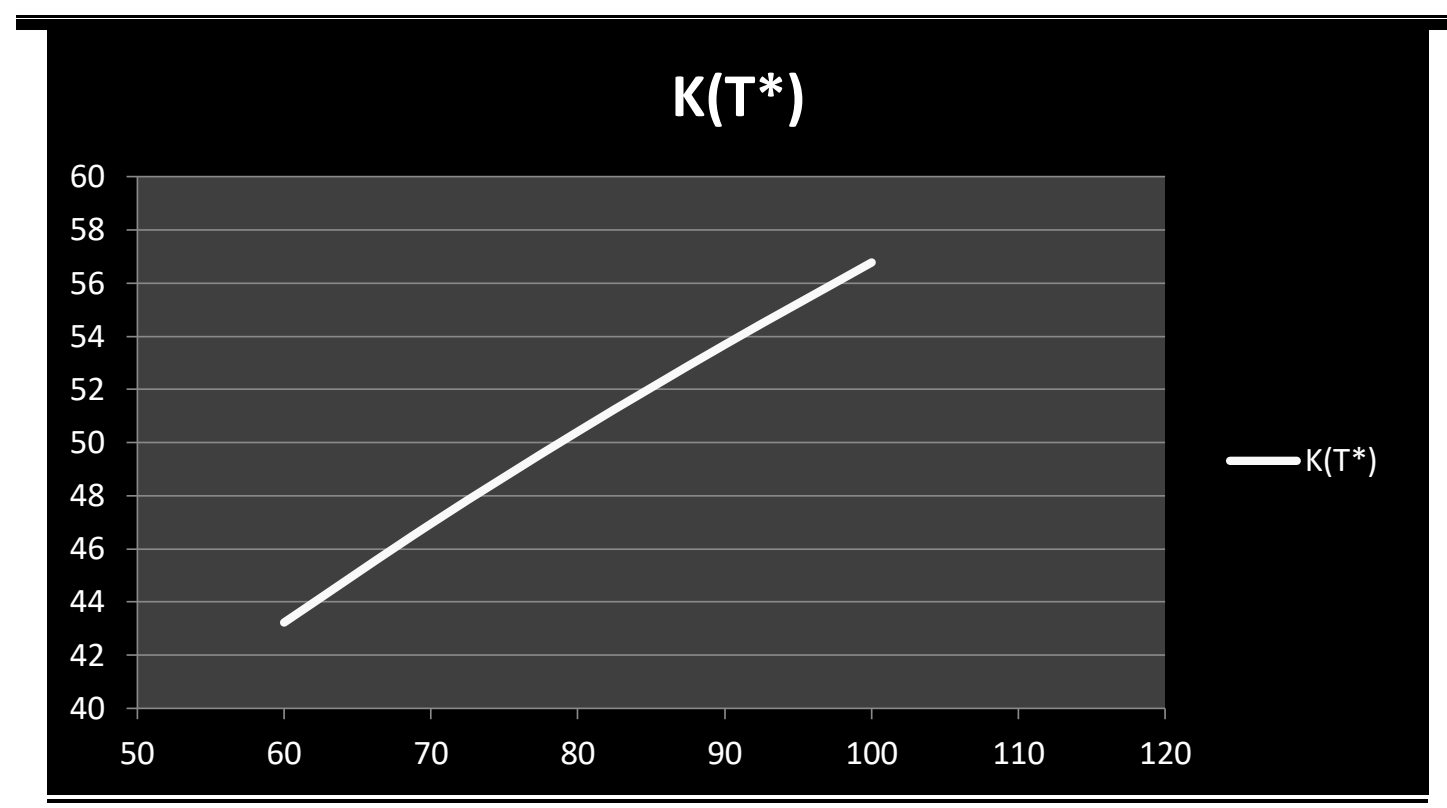

Fig. 4: Impact of $C_{2}$ on $K\left(T^{*}\right)$ : Crisp model

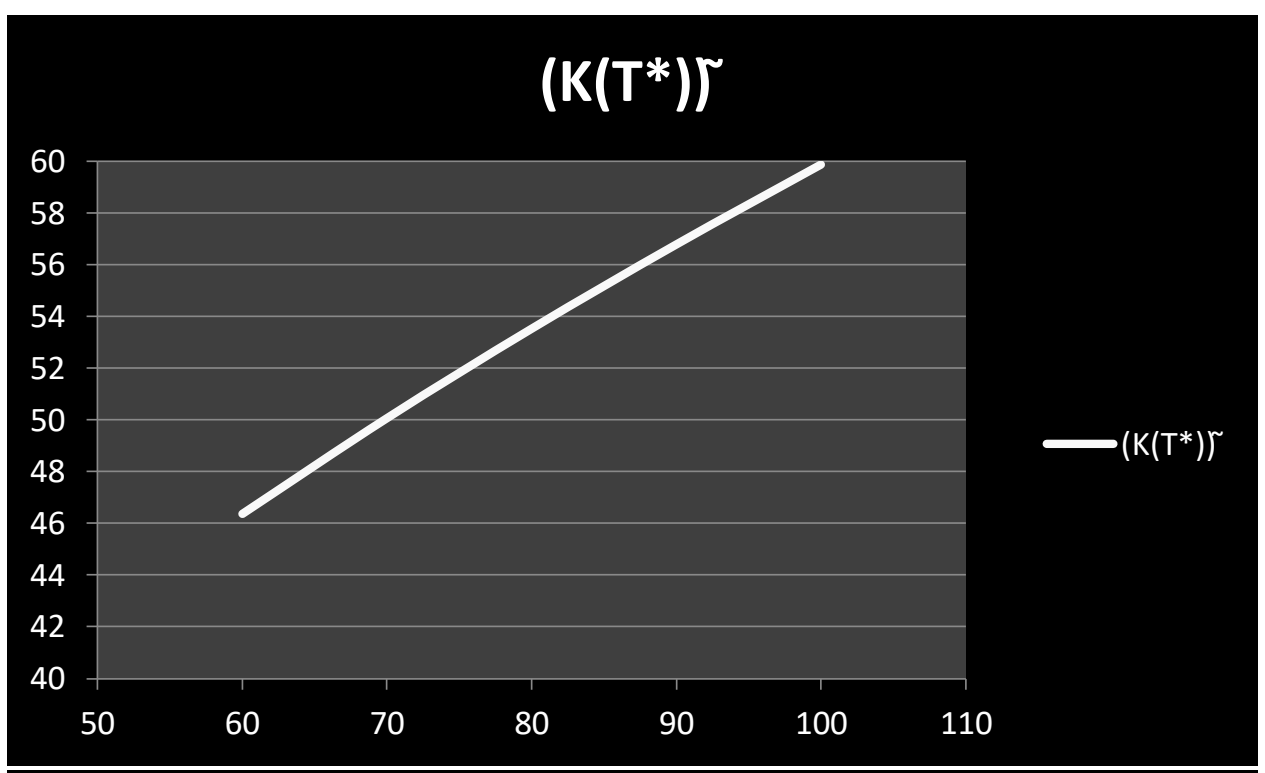

Fig. 5: Impact of $C_{2}$ on $\widetilde{K\left(T^{*}\right)}$ : Fuzzy model

Table 3: Sensitivity on $C_{1}$ :

\begin{tabular}{|c|c|c|c|c|c|}
\hline \multicolumn{2}{|c|}{ Change Value } & \multicolumn{2}{|c|}{$\overline{C \text { Crisp model }}$} & \multicolumn{2}{|c|}{ Fuzzy model } \\
\hline & & $\overline{K\left(T^{*}\right)}$ & $\overline{T^{*}}$ & $\widetilde{\overline{K\left(T^{*}\right)}}$ & $\widetilde{T^{*}}$ \\
\hline \multirow[t]{5}{*}{$C_{1}$} & 0.10 & 36.0927 & 4.069 & 39.0516 & 4.098 \\
\hline & 0.30 & 43.8291 & 3.393 & 46.8647 & 3.428 \\
\hline & 0.50 & 50.4065 & 2.975 & 53.5294 & 3.016 \\
\hline & 0.70 & 56.2313 & 2.684 & 59.4507 & 2.729 \\
\hline & 0.90 & 61.5158 & 2.465 & 64.8401 & 2.514 \\
\hline
\end{tabular}


International Journal of Engineering Applied Sciences and Technology, 2020 Vol. 5, Issue 1, ISSN No. 2455-2143, Pages 558-569

Published Online May 2020 in IJEAST (http://www.ijeast.com)

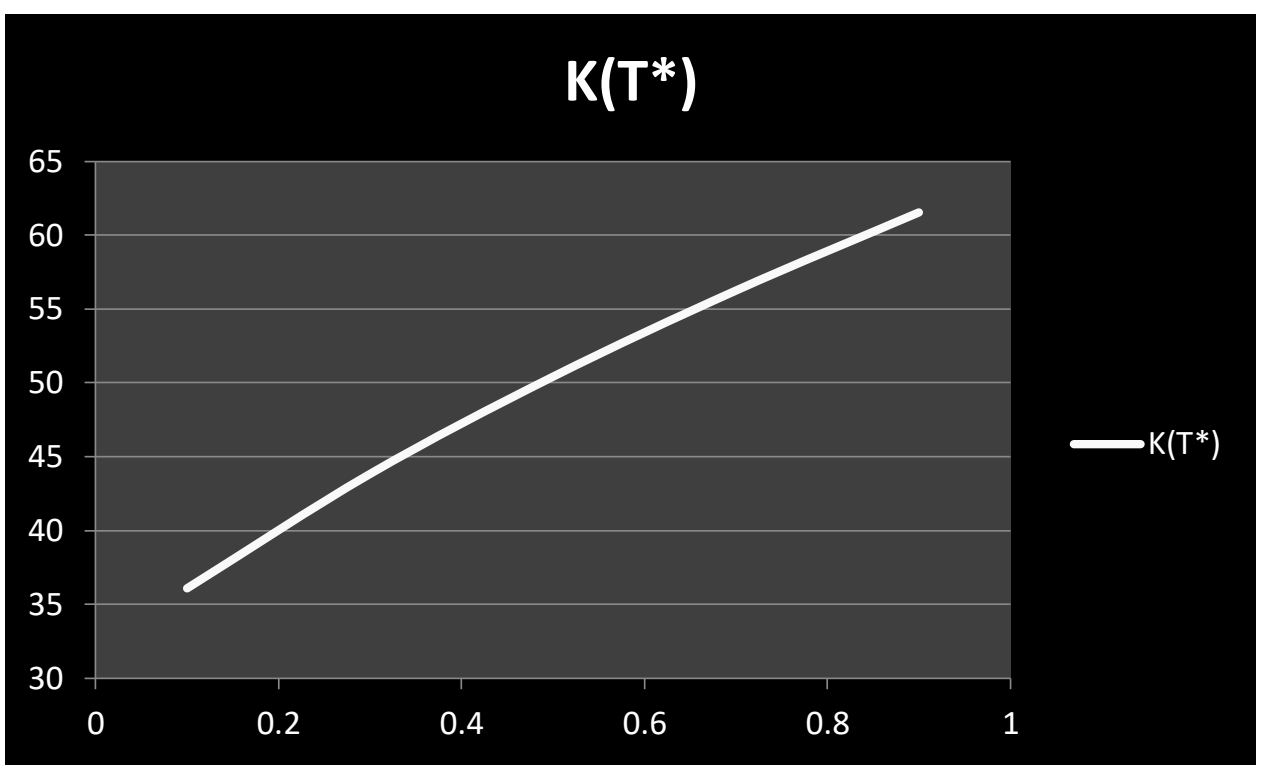

Fig. 6: Impact of $C_{1}$ on $K\left(T^{*}\right)$ : Crisp model

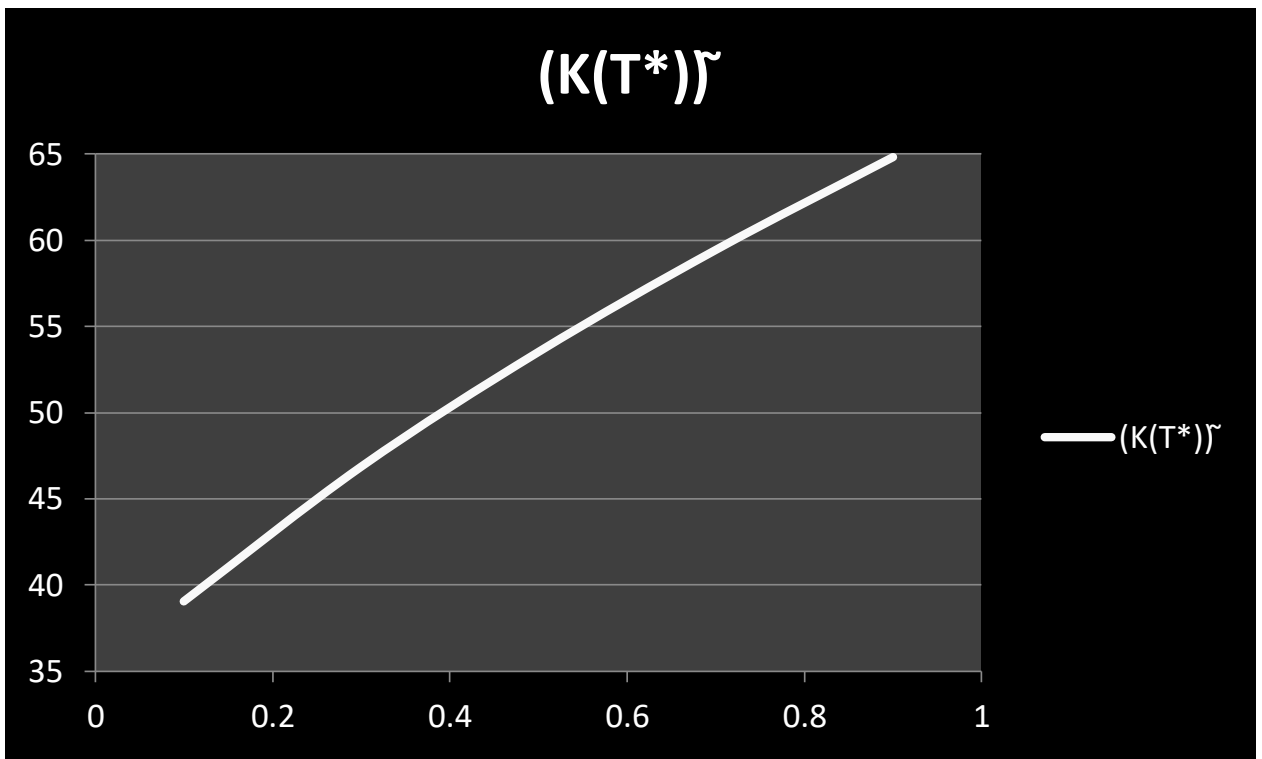

Fig. 7: Impact of $C_{1}$ on $\overline{K\left(T^{*}\right)}$ : Fuzzy mode

Table 4: Sensitivity on $C$ :

\begin{tabular}{|c|c|c|c|c|c|}
\hline \multicolumn{2}{|c|}{ Change Value } & \multicolumn{2}{c|}{ Crisp model } & \multicolumn{2}{c|}{ Fuzzy model } \\
\cline { 3 - 6 } \multicolumn{2}{|c|}{} & $K\left(T^{*}\right)$ & $T^{*}$ & $\left.\overline{K\left(T^{*}\right.}\right)$ & $\widetilde{T}^{*}$ \\
\hline \multirow{3}{*}{$C$} & 14 & 48.5454 & 3.112 & 50.0011 & 3.151 \\
\cline { 2 - 6 } & 16 & 49.4898 & 3.041 & 52.2789 & 3.081 \\
\cline { 2 - 6 } & 18 & 50.4065 & 2.975 & 53.5294 & 3.016 \\
\cline { 2 - 6 } & 20 & 51.2974 & 2.614 & 54.7544 & 2.955 \\
\cline { 2 - 6 } & 22 & 52.1641 & 2.855 & 55.9556 & 2.898 \\
\hline
\end{tabular}


International Journal of Engineering Applied Sciences and Technology, 2020 Vol. 5, Issue 1, ISSN No. 2455-2143, Pages 558-569

Published Online May 2020 in IJEAST (http://www.ijeast.com)

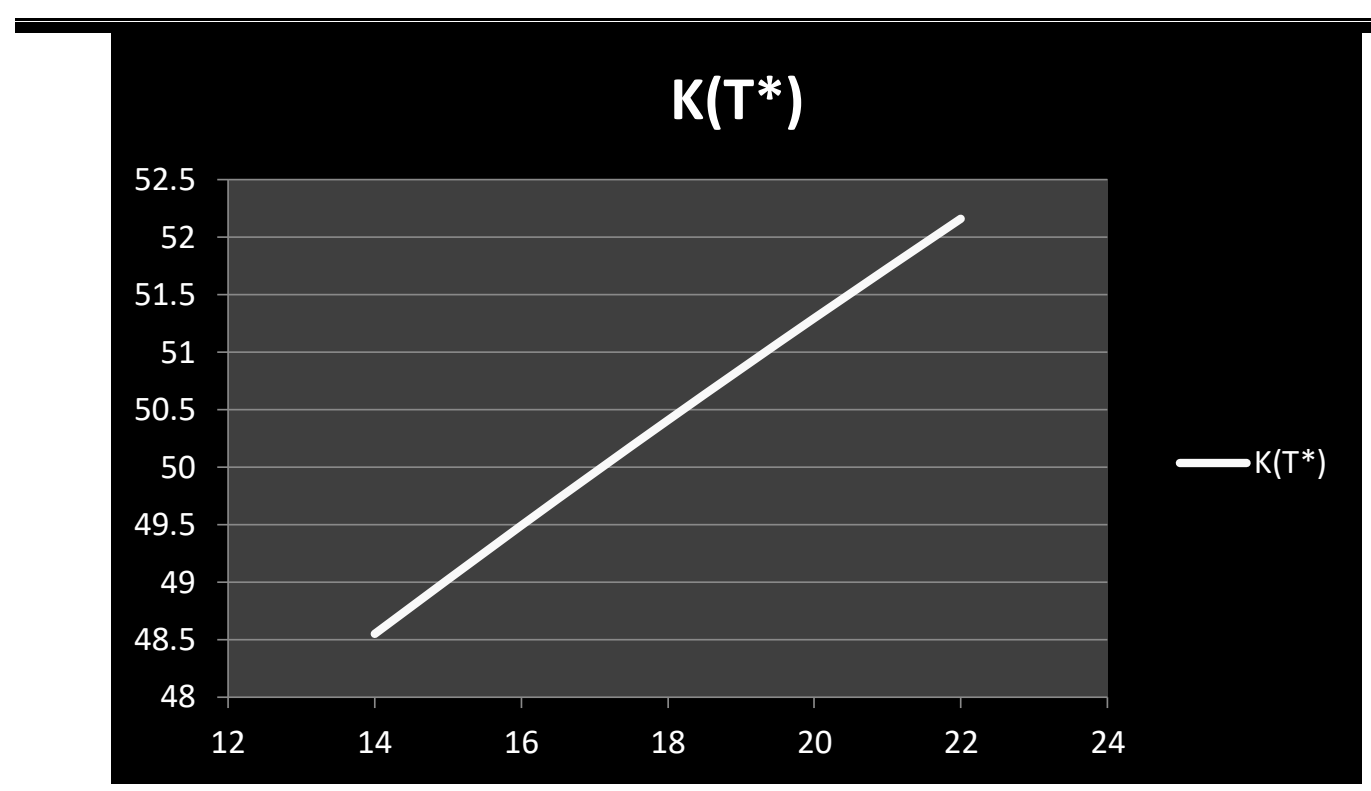

Fig. 8: Impact of $C$ on $K\left(T^{*}\right)$ : Crisp model

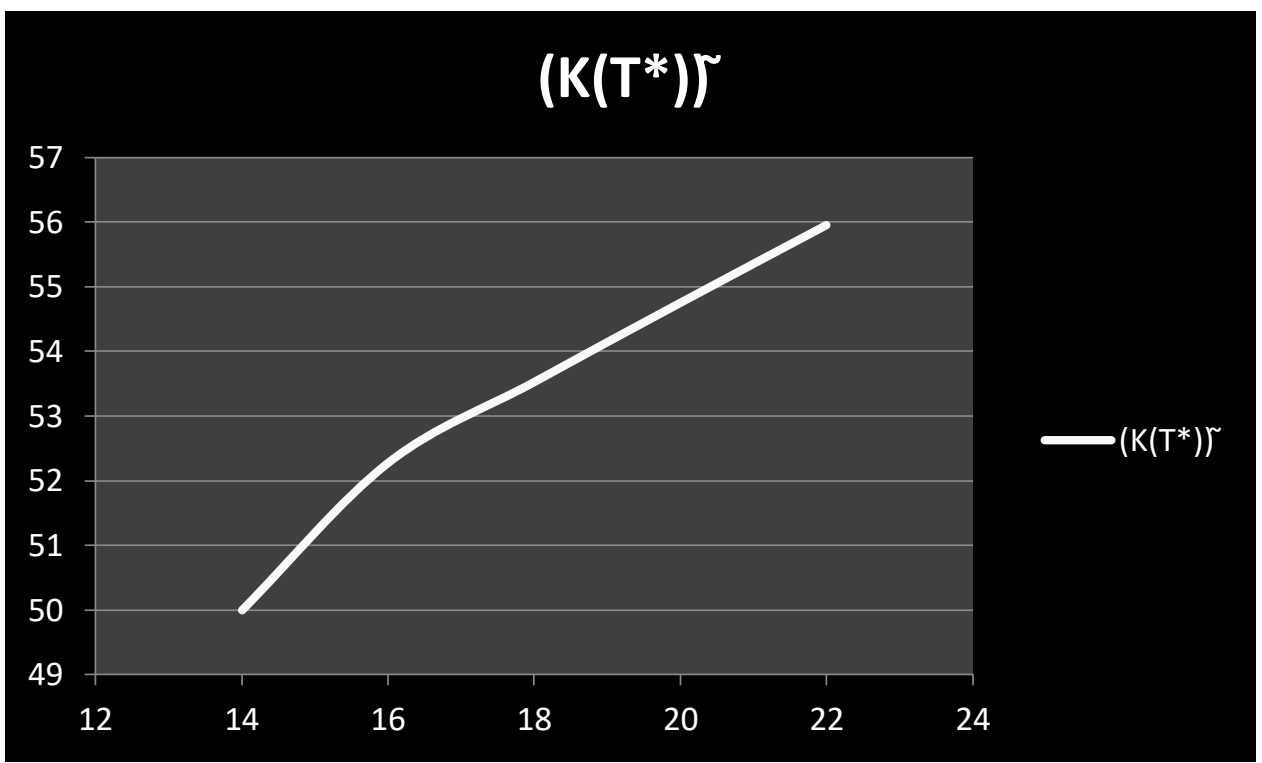

Fig. 9: Impact of $C$ on $\widetilde{K\left(T^{*}\right)}$ : Fuzzy model

Table 5: Sensitivity on $\theta$ :

\begin{tabular}{|c|c|c|c|c|c|}
\hline \multicolumn{2}{|c|}{ Change Value } & \multicolumn{2}{c|}{ Crisp model } & \multicolumn{2}{c|}{ Fuzzy model } \\
\cline { 3 - 6 } \multicolumn{2}{|c|}{} & $K\left(T^{*}\right)$ & $T^{*}$ & $\overline{K\left(T^{*}\right)}$ & $\widetilde{T}^{*}$ \\
\hline \multirow{3}{*}{$\theta$} & 0.01 & 45.8050 & 3.349 & 47.4191 & 3.385 \\
\cline { 2 - 6 } & 0.015 & 48.1976 & 3.154 & 50.5652 & 3.183 \\
\cline { 2 - 6 } & 0.02 & 50.4065 & 2.975 & 53.5294 & 3.016 \\
\cline { 2 - 6 } & 0.025 & 52.4629 & 2.832 & 56.3430 & 2.875 \\
\cline { 2 - 6 } & 0.03 & 54.3902 & 2.709 & 59.0291 & 2.753 \\
\hline
\end{tabular}


International Journal of Engineering Applied Sciences and Technology, 2020

Vol. 5, Issue 1, ISSN No. 2455-2143, Pages 558-569

Published Online May 2020 in IJEAST (http://www.ijeast.com)

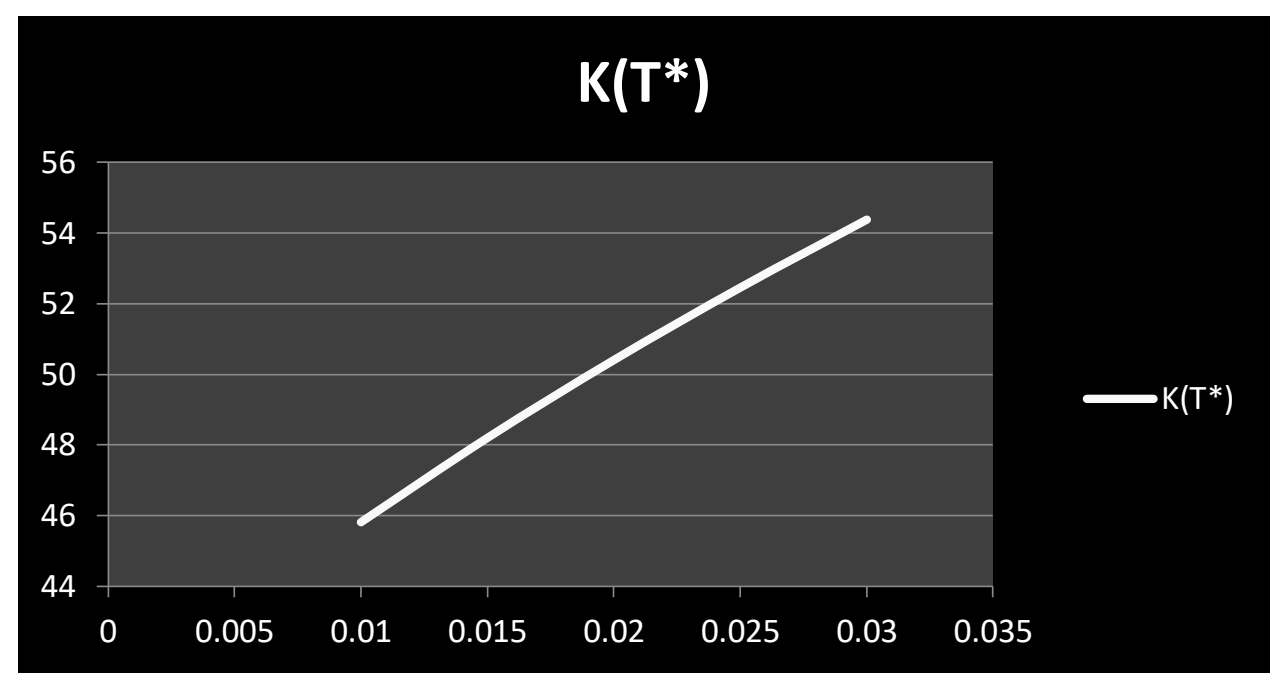

Fig. 10: Impact of $\theta$ on $K\left(T^{*}\right)$ : Crisp model

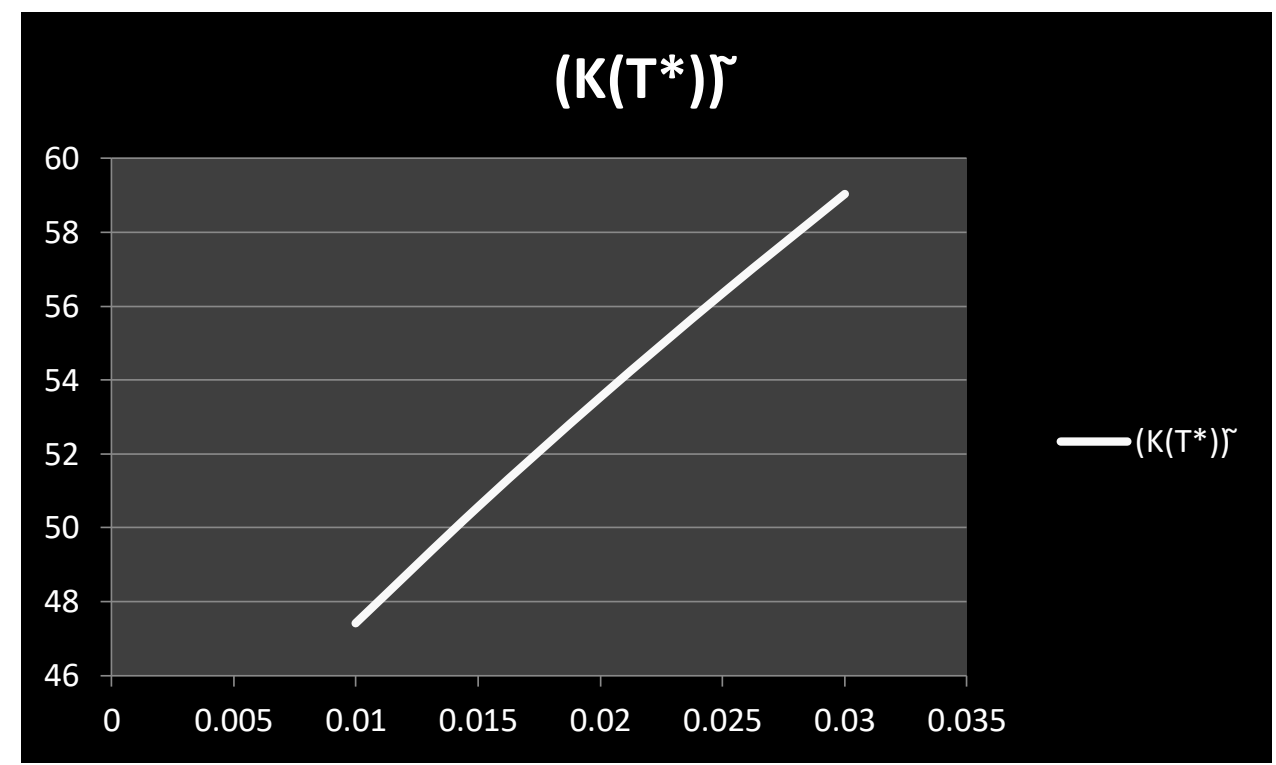

Fig. 11: Impact of $\theta$ on $\overline{K\left(T^{*}\right)}$ : Fuzzy mode

\section{Observations:}

It is observed from the above tables that:

i) In Crisp model, if the parameter $\mu$ is increased (or decreased), the value of optimum cycle time increases (or decreases) while the optimal total cost decreases (or increases). Further, in Fuzzy model, if the parameter $\mu$ is increased (or decreased) the value of optimum cycle time increases (or decreases) while the optimal cost increases. ii) The increases (or decrease) in set-up cost $C_{2}$ increases (or decreases) the total inventory cost for both the models.

iii) The total cost (for both the models) increases (or decreases) as the holding cost $C_{1}$ per unit time increases (or decreases).

iv) With the increase (or decrease) of the rate of deterioration $\theta$, the total inventory cost (for the two models) also increase (or decrease). 


\section{International Journal of Engineering Applied Sciences and Technology, 2020 Vol. 5, Issue 1, ISSN No. 2455-2143, Pages 558-569 \\ Published Online May 2020 in IJEAST (http://www.ijeast.com)}

v) As the deterioration cost $C$ per unit increase (or decrease), the total costs for the two models also increase (or decrease).

\section{CONCLUSION}

In the present chapter, we have dealt with a fuzzy inventory model where we have introduced the cycle time $\mathrm{T}$ as a Triangular Symmetric Fuzzy number. It is assumed the demand rate is constant for some time and then as a linear function of time. In our real life we generally find that the cycle time is uncertain. So keeping this situation in mind weI have tried to compare crisp model with the fuzzy model and have observed that the cycle time and the total cost obtained by Fuzzy model is greater than those obtained by Crisp model. The sensitivity analysis shows that the total cost of both the model increases as the cost associated with the model increases. In future, researchers can do more work about several types of demand, variable cost etc...

\section{REFERENCES}

1. Bellman R E, Zadeh LA., (1970). "DecisionMaking in a Fuzzy Environment". Manage Sci. 17(4), (pp. 141-164).

2. Dubois D, Prade H., (1978). "Operations on fuzzy numbers". Int. J. Sys.t Sci. 9(6), (pp. 613-26).

3. Park K S., (1987). "Fuzzy-set theoretic interpretation of economic order quantity". IEEE Trans. Syst. Man. Cybern. 17(6), (pp. 1082-4).

4. Wu k, Yao J-S., (2003).” Fuzzy inventory with backorder for fuzzy order quantity and fuzzy shortage quantity". Eur. J. Oper. Res. 150(20), (pp. 320-52).

5. Wang X, Zhao R., (2007). "Fuzzy economic order quantity inventory models without backordering". Tsinghua Sci. Technol. 12(1), (pp. 91-6).

6. Jinsong Hu, Hu J, Guo C, Xu R, Ji Y., (2010). "Fuzzy economic order quantity model with imperfect quality and service level". In: 2010 Chinese Control and Decision Conference [Internet]. Available from: http://dx.doi.org/10.1109/ccdc.2010.5498441

7. Lin C., Tan B. and Lee W. C., (2000). "An EOQ model for deteriorating items with timevarying demand and shortages". International Journal of System Science. 31(3), (pp. 39-400).

8. Ghosh S. K. and Chaudhuri K. S., (2004). "An order-level inventory model for a deteriorating item with Weibull distribution deterioration, Time-quadratic demand and shortages". AMO- Advanced Modeling and Optimization. vol.6, no. 1. (pp. 21-35).

9. Mishra N., Mishra S. P., Mishra S, Panda J, Misra U K., (2015). "Inventory model of deteriorating items for linear holding cost with time dependent demand". Mathematical Journal of Interdisciplinary Sciences. 4(1), (pp. 29-36).

10. Wang T. Y., Chen L. H., (2001). "A production lot size inventory model for deteriorating items with time-varying demand". Int. J. Syst. Sci. 32(6), (pp. 745-51).

11. Pal A K, Bhunia A K, Mukherjee RN., (2006). "Optimal lot size model for deteriorating items with demand rate dependent on displayed stock level (DSL) and partial backordering". Eur. J. Oper. Res. 175(2), (pp. 977-91).

12. Bera U. K., Bhunia A. K., Maiti M., (2013). "Optimal partial backordering two-storage inventory model for deteriorating items with variable demand". Int. J. Oper. Res. 16(1), (pp. 96)

13. He W., Wei H. E., Fuyuan X. U., (2013). "Inventory model for deteriorating items with time-dependent partial backlogging rate and inventory level-dependent demand rate". Journal of Computer Applications. 33(8), (pp. 2390-3).

14. Dutta D., Kumar P., (2015). “A partial backlogging inventory model for deteriorating items with time-varying demand and holding cost". Int. J. Math. Oper. Res. 7(3), (pp. 281).

15. Roy A., Samanta G. P., (2009). "Fuzzy continuous review inventory model without backorder for deteriorating items". Electronic Journal of Applied Statistical Analysis. 2, (pp. 58-66).

16. Jaggi K., et al., (2013). "Fuzzy inventory model for deteriorating items with timevarying demand and shortages". American Journal of Operational Research. 2(6), (pp. 81-92).

17. Yao J. S. and Chiang J., (2003). "Inventory without backorder with fuzzy total cost and fuzzy storing cost defuzzified by centroid and signed distance". European Journal of Operational Research. 148(2), (pp. 401-409).

18. Wang X., Tang W. and Zhao R., (2007). "Fuzzy economic order quantity inventory models without backordering". Tsinghua Science and Technology. 12(1), (pp. 91-96).

19. Kao C. and Hsu W. K., (2002). "A singleperiod inventory model with fuzzy demand". Computers \& Mathematics with Applications. 43(6-7), (pp. 841-848).

20. Dutta P., Chakraborty D. and Roy A. R., (2005). "A single-period inventory model with fuzzy random variable demand". 
Mathematical and Computer Modelling. 41(89), (pp. 915-922).

21. Bera U. K., Bhunia A. K., Maiti M., (2013). "Optimal partial backordering two-storage inventory model for deteriorating items with variable demand". Int. J. Oper. Res. 16(1), (pp. 96).

22. He W., Wei H. E., Fuyuan X. U., (2013). "Inventory model for deteriorating items with time-dependent partial backlogging rate and inventory level-dependent demand rate". Journal of Computer Applications. 33(8), (pp. 2390-3).

23. Dutta D., Kumar P., (2015). “A partial backlogging inventory model for deteriorating items with time-varying demand and holding cost”. Int. J. Math. Oper. Res. 7(3): (pp. 281).

24. Mishra N., Mishra S. P., Mishra S., Panda J., Misra U. K., (2015). "Inventory model of deteriorating items for linear holding cost with time dependent demand". Mathematical Journal of Interdisciplinary Sciences. 4(1), (pp. 29-36).

25. Priyan S., Manivannan P., (2017). “Optimal inventory modelling of supply chain system involving quality inspection errors and fuzzy effective rate". Opsearch. 54, (pp. 21-43). 